\title{
Automated Academic Assignment Submission and Management System: Proposed Design Using Agile Methodology
}

\author{
Muhammad Ehsan Rana ${ }^{1, *}$, Zailan Arabee ${ }^{2}$ and Darshini Amathlingam ${ }^{3}$ \\ 1,2,3 Asia Pacific University of Technology \& Innovation, 57000, Bukit Jalil, Kuala Lumpur, Malaysia \\ *Corresponding author. Email: muhd_ehsanrana@apu.edu.my
}

\begin{abstract}
Academic assignment submission and management is a complex process that involves sub-processes, including collecting, date-stamping, safe-keeping, marking, collation of results and feedback to students. Nevertheless, this concept needs to be implemented with the emerging trends of automating business processes and green computing. In this research, we attempted to discover the problems that arise from the manual assignment submission system by thoroughly studying the issues involved in this process and proposing an evolutionary development process to cater to these issues. Discussion is carried out to justify and choose an appropriate system development methodology for the implementation of this work. Since assignment submission is a vast area to be fully covered in this study, the proposed guidelines mainly cater for the features intended to overcome the issues discussed.
\end{abstract}

Keywords: Automated Assignment Submission, Assignment Management, Automated Assignment Tracking, Agile Methodology, Green Computing, Automated Business Process.

\section{INTRODUCTION}

This work is initiated considering the recent trends of automating business processes and the application of green computing. The traditional manual assignment submission and marking system can no longer satisfy the contemporary needs of lecturers and students. To cater modern-day requirements, researchers proposed a comprehensive Academic Assignment Submission and Management System [21-28]. This automated system will allow the students to submit their completed assignments through an online portal without printing them and submitting them manually. The proposed system is designed to improvise the existing traditional assignment submission processes, which typically comprises several lengthy manual procedures such as filling up a submission form and submitting it to the administration office in person. The main aim of this system is to automate the academic assignment submission processes and shorten the turnaround time to submit the assignment significantly. It will also help to obtain the feedback of all assessed assignments by reducing paper generation and, at the same time, providing a user-friendly interface for the users [29-32].
The proposed system will have three primary users: the student, the lecturer, and the administrative staff. It will provide different views of the system to authorize users according to their access privileges. Each of these users was provided with their specific functionality. The system will allow students to submit their assignments and receive their feedback and grades. Students who are not able to submit on time can fill in the extenuating circumstances field provided. For lecturers, the system will permit to create assignment questions and download submitted assignments as well as record grades and feedback against the submitted work. They will also be able to set due dates for each assignment submission. The functionalities of the administrative staff will include manage users, create new modules and assign lecturers. They will also be able to publish students' final grades and send reminders. This system is proposed to be used in institutes of higher learning like universities and colleges.

\section{BRIEF HISTORY OF ASSIGNMENT MANAGEMENT}

Nowadays, our society has become increasingly centred towards the management and manipulation of 
knowledge [1]. Assignment management has become one of the fundamental activities in education. Besides, in the manual assignment submission, where everything is done manually, all the assignments are recorded on papers, floppy disks, and emails. All the completed assignments by the student shall be submitted using hardcopy to the administration office. Apart from that, this method is inefficient and inconvenient to the students as it may cause several problems due to human errors as humans tend to make a mistake in a rush.

Human errors found in the manual assignment submission process will result in disordered printouts, damaged floppy disks and many other problems. Furthermore, the lecturers and students have neglected ongoing academic information, which can be used to help them improve their teaching and learning qualities and find out problems. This is why the assignment management method has become important to implement, providing both instructors and students with quality educational services [2].

The use of an online assignment management system began with the use of email in the year 1994. Figure 1 below shows the evolutionary development process from the old manual assignment management system to the current online system. Many factors have changed in infrastructure, individuals, course, experience, society, technology and organization. All these factors lead to the new online system.

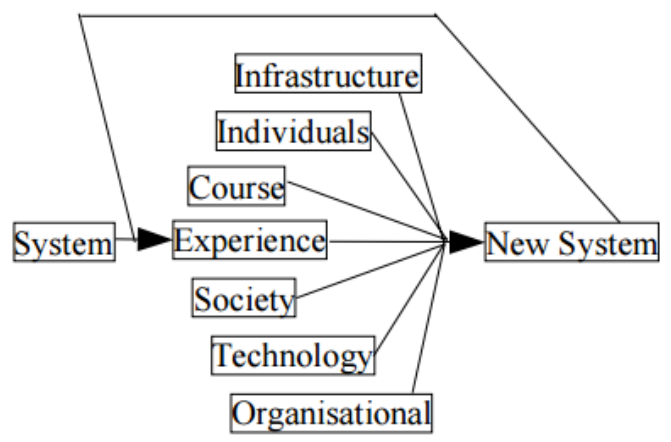

Figure 1 Evolutionary Development Process [3].

\section{PROBLEMS ASSOCIATED WITH TRADITIONAL SYSTEM}

This section describes the main problems associated with traditional assignment management and administration system.

\subsection{Human Errors}

According to [4], the traditional assignment submission involves complex procedures; hence human errors become more apparent. It resulted in an increased workload where the administrative staff must handle many assignments from different courses and intakes. For instance, when students submit the assignment documentation, staff need to keep track of the submission and pass all the assignments to the lecturers on time. Therefore, the complexity of this traditional assignment submission process increases the potential to make frequent errors such as misplacing the assignment documentation. On top of that, there are high chances that staff might forget to record the submission. The proposed system will eliminate this problem by tracking all the online submissions by submitting proof to all students after submitting successfully.

\subsection{Slow Delivery Time}

According to the study, traditional assignment offers slower transportation of assignment [5]. The traditional assignment submission processes will get slower due to the increase in students in a university or college. Since certain universities are still practicing the traditional assignment process and many students are submitting an assignment on a fixed date, this can cause long queues at the campus printing shops and the submission counters. Moreover, the traditional assignment submission also leads to slow delivery time due to the distance involved [6]. The proposed system will eliminate slow delivery time. Students can easily access the Internet and submit their completed assignments without manually submitting them at administration offices. On top of that, students staying far from the university do not need to worry about the distance. Just with a click of a button, they can submit the assignment from anywhere at any time.

\subsection{Long Turnaround Time}

As with the submission process, 93\% of students noted that their feedback was received faster electronically than using the traditional assignment submission system of posted feedback sheets [7]. Feedback is considered very effective when it is delivered on time to students, and it can be used as a guideline for improvement in the next assignment [8]. The current manual system takes a long turnaround time for the feedback form to reach the student. Therefore, it is essential to reduce the administration work and help in delivering the feedback form more efficiently. Besides, the feedback form can easily get lost; therefore, this proposed system allows students to view the electronic copy of the feedback form by accessing it online. Based on Table 1 below, the researchers conclude that $93 \%$ of students agreed that feedback reaches them quicker online compared to traditional. Moreover, Table 2 below shows that $56 \%$ of students prefer online feedback whereas only $6 \%$ of students prefer traditional. It can be concluded that $6 \%$ of students might not have access to the Internet therefore, they prefer traditional feedback. 
Table 1. Feedback Speed

\begin{tabular}{|l|l|}
\hline Relative Speed & $\%$ of Students \\
\hline Online much quicker & 53 \\
\hline Online slightly quicker & 40 \\
\hline Same & 7 \\
\hline Traditional slightly quicker & 0 \\
\hline Traditional much quicker & 0 \\
\hline
\end{tabular}

Table 2. Feedback Preference

\begin{tabular}{|l|l|}
\hline Preference & \% of Students \\
\hline Strongly prefer online & 23 \\
\hline Prefer online & 33 \\
\hline No preference & 32 \\
\hline Prefer traditional & 6 \\
\hline Strongly prefer traditional & 0 \\
\hline
\end{tabular}

\subsection{Extra Cost}

According to [7], traditional assignment submission costs more money. Humans tend to make mistakes, especially in a rush. If the assignment has already been printed but the student intended to modify it, it needs to be printed again, and extra cost will be added. The proposed system will eliminate the cost of printing and binding. Students will merely be required to submit the softcopy of the assignment to the 'Academic Assignment Submission and Management System'.

\subsection{Less Environment Friendly}

Lastly, the current traditional assignment management system is a manual procedure where many papers are consumed, not environment friendly. Much paper is utilized to keep track of the assignment throughout the assignment management lifecycle. Paper consumption has a "direct connection with global warming" because papers production comes from trees that provide carbon dioxide. According to [9], $42 \%$ of the forests cut every year go towards paper production. The proposed system reduced consumption of papers by allowing students to upload the assignment directly to the online portal.

\subsection{Storage and Retrieval}

Another issue is space-consuming due to physically storing assignment documentation [10]. Each student's assignments need to be stored in a place for a period for future references. It can eventually take up most of the space in the university, and it is not efficient. Apart from that, it takes a long process to retrieve the old assignment if requested by the lecturers or students. Valuable time is lost responding to the students, whereas the proposed system stores all the old assignments properly. Therefore, the staff can retrieve all the information within no time.

\subsection{Inefficient Recording System}

It is expected that students' assignments get lost or not found due to a vast number of submissions on a specific day. In this case, since everything is done manually, the administrative staff will not track the exact location of the student's assignment due to the inefficient recording system. All the assignment submission is recorded on papers, and there are times that staff forget to note down the submission. The proposed system solves the current problem by storing all the assignment submission details, including date and time in the database.

\subsection{Assignment Due Date}

The lecturer might change the assignment submission due date during the class session, and there are high chances that students fail to attend the class and not informed by their friends. It can cause the late submission of assignment. This problem can also be eliminated by proposing a new system. The 'Academic Assignment Submission and Management System' allows the lecturer to update any changes in the assignment's due date in the system. Therefore, all the students can check the online portal to know the actual submission date.

\subsection{Poor Feedback}

According to [11], handwritten feedback is found to be personal. Moreover, [12] have reported that students at times face difficulties in reading the handwritten feedback due to the illegible writing from their lecturers. It is one reason why students do not bother to get the feedback form from the lecturer because they think it is vague and ambiguous. This problem will be eliminated by proposing a new system. This system allows the lecturer to send feedback electronically. Electronic feedback encourages students to be responsible for their assignment and increase student participation [13].

\section{TYPES OF ONLINE ASSIGNMENT SUBMISSION}

Online assignment management can be broken down into three major categories: the manual email assignment management system, the automated email assignment management system, and the web-based assignment management system [4].

\subsection{Manual Email Assignment Management System}

Manual Email Assignment Management System was introduced in the year 1994-1995. Manual Email Assignment Management System is entirely manual, and it was designed for the usage of distance students only [5]. The students will attach the completed assignment document to the email and send it to the course 
coordinators email address. Once the lecturer successfully received the assignment documentation from the student, the lecturer will manually extract the assignment and save it. Besides, the lecturer will then mark the assignment and return it to the student using the email service [14]. This manual email assignment management system consists of the following steps:

- The registered user emails the completed assignment to the course coordinator which is the lecturer

- The lecturer manually extracts the submitted assignment by the student and saves the assignment.

- The lecturer then marks the assignment according to the marking scheme and return it to the student.

According to [14], $80 \%$ of the assignments that are sent through email, use text-based email programs and only $20 \%$ uses GUI based tools. Table 3 below shows the overview of this approach.

Table 3. Turnaround Time for Manual Email Assignment Management System

\begin{tabular}{|c|c|l|l|l|}
\hline Assignment & \# Submitted Online & \multicolumn{3}{|c|}{ Turnaround Time } \\
\hline & & Min & Avg & Max \\
\hline 1 & 20 & 9 & 33 & 46 \\
\hline 2 & 18 & 0 & 30 & 33 \\
\hline 3 & 18 & 2 & 12 & 26 \\
\hline 4 & 14 & 14 & 25 & 39 \\
\hline
\end{tabular}

\subsection{Automated Email Assignment Management System}

An automated email assignment management system was introduced after reviewing the manual assignment management system. This approach was fully automated, but it still relies on an email platform to manage the assignment submission [15]. This automated email assignment management system uses Perl Scripts.

Apart from this, the students sending their completed assignment to a valid email address. Once the lecturer receives the assignment from a particular student, the Perl script will access the assignment, then forwarding a copy to the marker and a message to the student indicating the assignment was received successfully. Once the lecturer has marked the assignment, he will send an email to the student. The Perl scripts will save the assignment documentation in achieving and publishing the grade [15].

Figure 2 shows the Assignment summary using traditional email assignment management system.

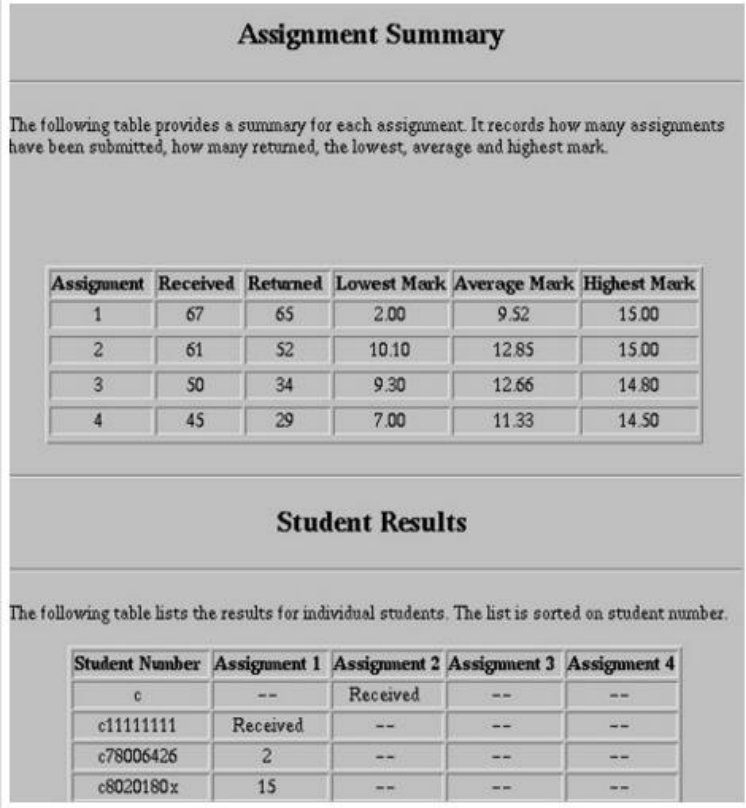

Figure 2 Assignment Summary.

Several issues were raised after implementing this system, such as encoding issues and inappropriate header formatting issues. For example, the encoding issue arises when the client computer uses a different encoding format for the email system. Table 4 below shows the turnaround time for automated email assignment management system

Table 4. Turnaround Time for Automated Email Assignment Management System

\begin{tabular}{|c|c|l|l|l|}
\hline Assignment & \# Submitted Online & \multicolumn{3}{|c|}{ Turnaround Time } \\
\hline & & Min & Avg & Max \\
\hline 1 & 57 & 0 & 9 & 31 \\
\hline 2 & 50 & 0 & 9 & 19 \\
\hline
\end{tabular}

\subsection{Web-based Assignment Management System}

Web assignment management system was introduced after the automated email assignment management system. After introducing this approach, the email system has been removed and no longer used for the assignment submission [16]. This process starts when the student accesses a new web page and logs in to the system using the valid username and password. Besides, once the student successfully logged into the system, the student will select the assignment documentation and submit it to the web page.

Apart from this, the lecturer will have to $\log$ in and use a valid username and password to get accessed to the assignment submitted by the student. After marking the assignment, the lecturer then provides the grade and feedback/comment to the student. The student can log in to the system again to view the grade of their assignment [16]. Table 5 below shows the turnaround time for webbased assignment management system. 
Table 5. Turnaround Time for Web-based Assignment Management System

\begin{tabular}{|c|c|l|l|l|}
\hline Assignment & \# Submitted Online & \multicolumn{3}{|c|}{ Turnaround Time } \\
\hline & & Min & Avg & Max \\
\hline 1 & 100 & 1 & 2 & 7 \\
\hline 2 & 98 & 0 & 17 & 30 \\
\hline 3 & 99 & 0 & 5 & 14 \\
\hline
\end{tabular}

\section{BENEFITS OF ONLINE ASSIGNMENT SUBMISSION}

Following are the key benefits of implementing an online assignment management system:

\subsection{Accessible from Anywhere}

Since all the assignment will be submitted to a specific online portal and stored in a proper database, the system users will be able to access the assignment from anywhere, anytime, with an internet connection [17].

\subsection{Reduce Paper Handling}

Paper handling will be greatly reduced as every assignment will be done electronically. The students can eliminate the need to photocopy the assignment documentation in order to submit it. Therefore, the students can cut cost on printing the assignment. Besides, it also reduces the physical storage of assignment documentation as the lecturers will be receiving assignments electronically [17].

\subsection{Easy Communication}

Since all the submissions, markings and feedback will be handled online, the communication between users will be easy. All users can access the system at any point in time to check whether the assignment has been marked, allowing feedback/comments. Students can easily access the assignment marks without having to meet the lecturer personally [4].

\subsection{Tracking of Submission}

It will be an easy task to track the assignment submission as all the documents uploaded to the system will be stored safely in the proper database [4].

\subsection{Simple to Use}

The online assignment management system is straightforward and easy to use. In fact, students do not have to fill in the submission forms manually [17].

\section{PROPOSED SYSTEM DESIGN USING AGILE METHODOLOGY}

A system development methodology represents a framework that is basically used to plan, structure, and control information system development [18]. There are various software development methodologies available in the market. An appropriate methodology needs to be selected in order to meet the requirement of the project through analysing the factor of success. After looking into many factors such as the quality, the time allocated for development, and the nature of the project, a flexible and iterative methodology would be appropriate. After considering those factors, the researchers decided that best-suited methodology in developing the Academic Assignment Submission and Management System is Agile Methodology. The most popular agile methodology includes extreme programming (XP), Scrum and Agile Unified Process (AUP). Each agile method has uniqueness in its approach, in which they all share a common vision and core values. The agile methodology includes iteration and continuous feedback to deliver a software system individually [19]. The term Agile as it relates to modern software development was being used during the 1990s in various published articles. Agile methodology appreciates a documentation driven software development processes, and it acts like a traditional way of developing software [19].

Agile methodology was chosen because it can respond to changing requirements quickly. By using agile, the team do not have to invest a lot of time and effort because the customer requirements will not be changed at the time of delivery. Moreover, there will be no space for guesswork as there will be face to face communication and continuous inputs from the customer. Apart from that, the documentation is crisp and to the point to save time. Figure 3 below shows the Agile Unified Process that was chosen as a methodology for this proposed project.

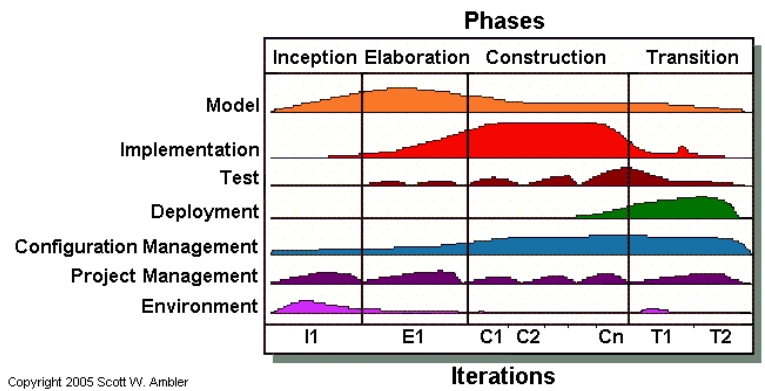

Figure 3 Agile Unified Process [20].

The agile methodology that was chosen is Agile Unifies Process (AUP). The Agile Unified Process (AUP) is the agile version of the Rational Unified Process (RUP) [20]. AUP involves four phases with seven disciplines. 


\subsection{Agile Unifies Process (AUP) Phases}

The serial nature of Agile Unified Process is captured in its four phases:

\subsubsection{Inception}

The inception phase identifies the project's initial scope, that represents the possible architecture for the Academic Assignment Submission and Management System. It is used to gain initial funding and stakeholder approval.

\subsubsection{Elaboration}

The elaboration phase proves the architecture of the Academic Assignment Submission and Management System.

\subsubsection{Construction}

The construction phase builds a working software for the Academic Assignment Submission and Management System by following an incremental plan that allows meeting the highest priority needs of the project stakeholder.

\subsubsection{Transition}

The transition phase validates and deploys the Academic Assignment Submission and Management System into the production environment.

\subsection{Agile Unifies Process (AUP) Disciplines}

Disciplines are performed iteratively, defining the activities, validate, and deliver the working software. The seven disciplines are as follows:

\subsubsection{Model Workflow}

The first step of AUP is the model workflow which begins with the Inception phase. The objective is to understand the business organisation, to define the problem and what the user needs, to identify the best solution [20].

\subsubsection{Implementation}

During the Construction phase, the model is transformed into executable code and tested thoroughly by unit tests [20].

\subsubsection{Test}

During this phase, an objective evaluation of the developed application is performed. These phases include unit-testing, usability testing, and useracceptance testing [20].

\subsubsection{Deployment}

Ensures that the newly developed application is successfully deployed [20].

\subsubsection{Configuration Management}

These phases ensure that the artefacts of the system are tracked and adequately versioned [20].

\subsubsection{Project Management}

These activities in this project management include risk management and coordinating external resources to ensure that the Academic Assignment Submission and Management System is delivered within scope, cost, and time [20].

\subsubsection{Environment}

The Environment Workflow makes sure that the project occurs in an environment suitable enough to ensure the success of the project [20].

\section{CONCLUSION}

This research is carried out to solve the current manual assignment submission process, which takes a long turnaround time to submit. On the other hand, the administrative staff will find it easy to extract the reports online. Besides, students' assignments will be secured and protected. In conclusion, considering the arguments above, agile methodology is one of the most suitable options for developing the proposed Academic Assignment Submission and Management System using a web-based approach. The researchers proposed that the system should be implemented on the cloud. The advantage of using cloud is that the proposed system will be running live 24/7 and can be accessed using handheld devices without the concerns of managing its infrastructure locally. Some limitations have also been identified in the proposed system, such as the level of security. This research does not cater for the security concerns in the assignment submission process. A proper encryption mechanism needs to be implemented to make this system secure. Moreover, the proposed system does not use rubrics for assignment marking. Lecturers are required to mark student's assignment offline. These limitations will be taken into consideration and will be included in the future enhancements.

\section{REFERENCES}

[1] Furneaux, Craig. "How Does Information Technology Impact the Methods, Potential and Purpose of Education?". N.p., 2004. Web. 13 Feb. 2016. 
[2] Sun, Xiaoyu. "An Assignment Management System". (2002): n. pag. Web. 8 Feb. 2016.

[3] Jones, D. \& Behrens, S., 2003. Online assignment management: an evolutionary tale. 36th Annual Hawaii International Conference on System Sciences, 2003. Proceedings of the, 00(C), pp.1-9. Available at: http://www.hicss.hawaii.edu/HICSS36/HICSSpape rs/ETWBE08.pdf.

[4] Jones, D., 2002. 5311607ee61f6ad6275514b3448efa3805960c23@ davidtjones.wordpress.com. Available at: https://davidtjones.wordpress.com/publications/thr ee-generations-of-online-assignment-management/.

[5] Bancroft, Peter et al. "Web-Based Assignment Submission and Electronic Marking". (2003): n. pag. Print.

[6] Karim, J.A. \& Amir, a, 2012. A Case Study of an Online Assignment Submission System at UOM, 6(8), pp.1451-1453. Available at: http://waset.org/publications/2481/a-case-study-ofan-online-assignment-submission-system-at-uom.

[7] Bridge, P. \& Appleyard, R., 2008. A comparison of electronic and paper-based assignment submission and feedback. British Journal of Educational Technology, 39(4), pp.644-650.

[8] Boyum, G., 2008. Online Submission. Academy of Human Resource Development International Research Conference in the Americas, 38, pp.2-3.

[9] Forest Ethics, 2011. Forest Ethics Forest Ethics 2011 Highlights. Available at: http://www.forestethics.org/sites/forestethics.huang .radicaldesigns.org/files/Annual_Report_2011_For estEthics.pdf.

[10] Lexmark, 2010. Streamlining Paper-Based Document Processes with Distributed Capture Solutions. Available at: http://www.officeproductnews.net/sites/default/file s/Distributed-Capture-White-Paper.pdf.

[11] Morgan, V.L., 2006. No Title, 5(3), pp.333-340. Available http://www.ncolr.org/jiol/issues/pdf/5.3.8.pdf.

[12] Ni Chang, A. et al., 2012. Electronic Feedback or Handwritten Feedback: What Do Undergraduate Students Prefer and Why? Journal of Teaching and Learning with Technology, 1(1), pp.1-23. Available at: http://jotlt.indiana.edu/article/view/2043.

[13] Seliem, S. \& Ahmed, a, 2009. Missing: Electronic Feedback in Egyptian EFL Essay Writing Classes.
Online Submission, p.36. Available at: http://files.eric.ed.gov/fulltext/ED505841.pdf.

[14] Cranston, Mary et al. "What Makes ICT Implementation Successful: A Case Study Of Online Assignment Submission". (2005): n. pag. Print.

[15] Elaiza, Orit Naor, and Nitza Geri. "Not As Easy As Email: Tutors' Perspective Of An Online Assignment Submission System". (2009): n. pag. Print.

[16] Bancroft, P. and Hynd, J. (2011) 'Web-based assignment submission Queensland University of Technology'.

[17] Oudce, "Benefits of Using Online Assignment Handling". (2010): n. pag. Print.

[18] Centers for Medicare \& Medicaid Services (CMS) Office of Information Service. (2005). Selecting a development approach. Available: http://www.cms.gov/SystemLifecycleFramework/ Downloads/SelectingDevelopmentApproach.pdf. Last accessed 28th June 2011.

[19] Szalvay, Victor. "An Introduction to Agile Software Development". (2004): n. pag. Print.

[20] Ambler, Scott W. Agile Modeling. New York: J. Wiley, 2002. Print.

[21] Kiran, P., Parameshachari, B.D., Yashwanth, J. and Bharath, K.N., 2021. Offline Signature Recognition Using Image Processing Techniques and Back Propagation Neuron Network System. SN Computer Science, 2(3), pp.1-8.

[22] Shivappriya, S.N., Karthikeyan, S., Prabu, S., Pérez de Prado, R. and Parameshachari, B.D., 2020. A modified ABC-SQP-based combined approach for the optimization of a parallel hybrid electric vehicle. Energies, 13(17), p.4529.

[23] Kumar, M.K., Parameshachari, B.D., Prabu, S. and liberata Ullo, S., 2020, September. Comparative Analysis to Identify Efficient Technique for Interfacing BCI System. In IOP Conference Series: Materials Science and Engineering (Vol. 925, No. 1, p. 012062). IOP Publishing.

[24] Nguyen, N.T., Liu, B.H., Pham, V.T. and Luo, Y.S., 2016. On maximizing the lifetime for data aggregation in wireless sensor networks using virtual data aggregation trees. Computer Networks, 105, pp.99-110.

[25] Liu, B.H., Nguyen, N.T., Pham, V.T. and Yeh, Y.H., 2015. A maximum-weight-independent-set-based algorithm for reader-coverage collision avoidance 
arrangement in rfid networks. IEEE Sensors Journal, 16(5), pp.1342-1350.

[26] Pham, D.V., Nguyen, G.L., Nguyen, T.N., Pham, C.V. and Nguyen, A.V., 2020. Multi-topic misinformation blocking with budget constraint on online social networks. IEEE Access, 8, pp.7887978889.

[27] Subramani, P., Rajendran, G.B., Sengupta, J., Pérez de Prado, R. and Divakarachari, P.B., 2020. A block bi-diagonalization-based pre-coding for indoor multiple-input-multiple-output-visible light communication system. Energies, 13(13), p.3466.

[28] Bhuvaneswary, N., Prabu, S., Karthikeyan, S., Kathirvel, R. and Saraswathi, T., 2021. Low Power Reversible Parallel and Serial Binary Adder/Subtractor. Further Advances in Internet of Things in Biomedical and Cyber Physical Systems, p.151.

[29] Z. Guo, K. Yu, A. Jolfaei, A. K. Bashir, A. O. Almagrabi, and N. Kumar, "A Fuzzy Detection System for Rumors through Explainable Adaptive Learning", IEEE Transactions on Fuzzy Systems, doi: 10.1109/TFUZZ.2021.3052109.

[30] K. Yu, L. Tan, M. Aloqaily, H. Yang, and Y. Jararweh, "Blockchain-Enhanced Data Sharing with Traceable and Direct Revocation in IIoT", IEEE Transactions on Industrial Informatics, doi: 10.1109/TII.2021.3049141.

[31] K. Yu, L. Lin, M. Alazab, L. Tan, B. Gu, "Deep Learning-Based Traffic Safety Solution for a Mixture of Autonomous and Manual Vehicles in a 5G-Enabled Intelligent Transportation System", IEEE Transactions on Intelligent Transportation Systems, doi: 10.1109/TITS.2020.3042504.

[32] Z. Guo, Y. Shen, A. K. Bashir, M. Imran, N. Kumar, D. Zhang and K. Yu, "Robust Spammer Detection Using Collaborative Neural Network in Internet of Thing Applications", IEEE Internet of Things Journal, vol. 8, no. 12, pp. 9549-9558, 15 June15, 2021, doi: 10.1109/JIOT.2020.3003802. 